Article

\title{
Effect of Ultraviolet Irradiation on Osseointegration of Dental Implants: A Comparative Histomorphometric Study in Canine Models
}

\author{
Chunui Lee ${ }^{1,+} \mathbb{D}$, Seung-Mi Jeong ${ }^{2,+}$, Hyun-Woo Yang ${ }^{3}$ and Byung-Ho Choi ${ }^{1, *(D)}$ \\ 1 Department of Oral and Maxillofacial Surgery, Yonsei University Wonju College of Medicine, \\ Wonju 26426, Korea; chunuilee@naver.com \\ 2 Department of Prosthodontics, Yonsei University Wonju College of Medicine, Wonju 26426, Korea; \\ smj3@yonsei.ac.kr \\ 3 Department of Dentistry, Yonsei University Wonju College of Medicine, Wonju 26426, Korea; \\ bachooo@naver.com \\ * Correspondence: choibh@yonsei.ac.kr \\ $\dagger$ These authors contributed equally to this work.
}

Received: 14 May 2020; Accepted: 17 June 2020; Published: 19 June 2020

\begin{abstract}
Recent studies have focused on achieving sound osseointegration applying methods of surface reprocessing of dental implants using ultraviolet (UV) irradiation. However, there have been few reports on the effect of UV irradiation on osseointegration in both the short and long term, and experimental studies using the canine model do not exist. Therefore, the aim of this study was to determine the short- and long-term degree of osseointegration of dental implants according to UV irradiation using a histometric analysis in canine models. Four beagles were used for this study and 24 dental implants were placed. Six implants were inserted with flapless protocols in each mandible. Half of the implants were UV-irradiated prior to implantation. UV-treated and untreated implants were placed one after the other; implant stability was recorded using the implant stability test (IST) immediately after implantation and every seven days thereafter. Two of the beagles were sacrificed after four weeks and the other two after 12 weeks. The implants were removed in block sections and were evaluated histomorphologically and statistically. As a result, we found no statistically significant differences in the mean IST values and in bone-to-implant contact (BIC) in all groups at 4 and 12 weeks.
\end{abstract}

Keywords: UV-irradiation; dental implant; bone-to-implant contact; implant stability test

\section{Introduction}

Recently, rehabilitation of masticatory function using dental implants has become a treatment option [1]. One of the most important considerations for the success of dental implants is the occurrence of osseointegration [2,3]. Osseointegration can be influenced by numerous factors. Marco et al. reported that osseointegration can be affected by design of the implant, chemical composition, topography of the surface, and materials such as shape, length, and diameter [4]. Soballe et al. stated that the mechanical stability and loading conditions can affect osseointegration [5]. Linder et al. stressed that the status of the host bone bed and its intrinsic healing potential should also be considered as important factors for successful osseointegration [6].

Primary stability, which means mechanical engagement with cortical bones, and secondary stability, which means deposition of new bone that reaches the peak point at 8 weeks and stabilizes at 12 weeks, act as factors in osseointegration [7-10]. Stability dip, the cross point between primary 
stability and secondary stability at four weeks of implant placement, should also be considered, and how stability is endured affects osseointegration [11].

To achieve successful osseointegration, osteoblasts must contact the implant surface well [12], a process that varies depending on implant surface treatment and roughness of the implant surface [13]. The debate continues over smooth and rough surfaces, that is, between the sandblast large grit acid etching (SLA) method and other methods such as resorbable blast media, acid etching, anodizing, plasma spray, and hydroxyapatite coating [14,15]. One clinical issue is how to reprocess implant surfaces treated with SLA [16]. Over time, the newly fabricated titanium surface becomes hydrophobic due to hydrocarbon adherence and surface charge changes, which has been known to degrade its biochemical ability $[17,18]$. To solve this problem, ultraviolet (UV) irradiation on titanium surfaces was developed to remove hydrocarbons and restore reduced biochemical capabilities [18,19].

One of the main clinical issues has been securing stability of inserted implants, which may be affected by bone-implant contact [8,20]. Many studies were conducted to quantify implant stability [21]. Perio test values (PTVs) using Periotest ${ }^{\circledR}$ (Medizintechnik Gulden, Modautal, Germany), implant stability quotients (ISQs) using Osstell ${ }^{\circledR}$ (Osstell AB, Gothenburg, Sweden) and implant stability tests (ISTs) using Anycheck ${ }^{\circledR}$ (Neobiotech, Seoul, Korea) have been used [12,22]. Unlike the above products, Anycheck ${ }^{\circledR}$ has an all-in-one design, which makes it easy to manipulate and allow multiple implants to be measured quickly at the same time. In addition, healing abutments can be retained without removal, which may minimize crestal bone loss [23].

According to a series of papers, a statistically significant relationship exists between UV irradiation and osseointegration [17-19]. UV treatment can produce photofunctionalization on aged titanium surface, turning it into a bioactive and osteoconductive surface, which can significantly increase and improve osseointegration by removing the hydrocarbons from their contaminated surfaces [17-19]. However, since the above claims were obtained in vitro, how UV photofunctionalization contributes to osseointegration in vivo is still unknown.

Therefore, the aims of this study were, first, to evaluate the difference of implant stability between UV-irradiated and non-irradiated groups and, second, to measure the differences in bone-to-implant contact (BIC) values histologically and statistically after 4 and 12 weeks of implantation in canine models.

\section{Materials and Methods}

Four male beagle dogs in healthy condition, each weighing over $10 \mathrm{~kg}$ (range: 10 to $15 \mathrm{~kg}$ ), were used in this study; the experiment protocol was approved by the Institutional Animal Care and Use Committee of Yonsei University at Wonju College of Medicine (YWC-180327-1). All mandibular premolars and the first and second molars were extracted surgically; the alveolus was flattened with a round bur to create the experimental model with flat edentulous ridges for implantation. After four weeks of healing, computed tomography (CT) scans were captured by radiologic technicians to virtually plane implant placement and to fabricate surgical guides. The 24 titanium implants used for the study were screw-shaped, with a diameter of $3.8 \mathrm{~mm}$ and a length of $10.0 \mathrm{~mm}$ (UFII ${ }^{\circledR}$, DIO Implant Co., Pusan, Korea), and were inserted using CT-guided flapless implant surgery thereafter.

\subsection{Photofunctionalization of Dental Implants and CT-Guided Flapless Implant Placement}

The CT images of maxilla and mandible were taken prior to implantation; surgical templates were fabricated using CT images and oral scanners. Digital impressions of remaining teeth and edentulous ridges of the jaws were recorded using an intraoral scanner $\left(T_{R I O S}{ }^{\circledR}\right.$, 3Shape $\mathrm{A} / \mathrm{S}$, Copenhagen, Denmark) after CT images were acquired. Digital stereolithography (STL) files generated from the intraoral scans and Digital Imaging and Communications in Medicine (DICOM) data acquired from CT images were merged using a virtual implant planning software (Implant Studio ${ }^{\circledR}$, 3Shape, Copenhagen, Denmark).

After merging the images, six implants were positioned with a safety zone of at least $4 \mathrm{~mm}$ around each implant. After completing the simulation (virtual treatment planning), tooth-supported surgical 
templates were designed and printed using a 3-dimensional printer (PROBO ${ }^{\circledR}$, DIO Implant Co., Pusan, Korea).

Computer-guided flapless implant surgery was performed using the surgical template under general ( $5 \mathrm{mg} / \mathrm{kg}$ ketamine and $2 \mathrm{mg} / \mathrm{kg}$ xylazine) and local (2\% lidocaine with 1:80,000 epinephrine) anesthesia. Osteotomies were performed according to the drill sequence using the surgical guides. Six implants (length: $10 \mathrm{~mm}$; diameter: $4.0 \mathrm{~mm})\left(\mathrm{UFII}^{\circledR}\right.$, DIO Implant Co., Pusan, Korea) were inserted into the edentulous mandibles; the healing abutments were tightened to $30 \mathrm{Ncm}$ using a torque wrench sequentially.

Prior to implant placement, 12 implants were photofunctionalized by UV irradiation before implantation for 15 minutes by the UV light device (TheraBeam Affiny, Ushio, Tokyo, Japan), whereas the remaining 12 implants remained non-irradiated. The photofunctionalization-induced change in surface properties from hydrophobic to hydrophilic was tested by dipping the implant surfaces into the distilled water. The photofunctionalization was confirmed by watching the water on the surface of the implants rise in a spiral immediately after being dipped into the water (Figure 1) [19]. UV-treated and untreated implants were inserted one by one into the mandibles, and the healing abutments (UFII ${ }^{\circledR}$, DIO Implant Co., Pusan, Korea) were connected to the implants (Figure 2).

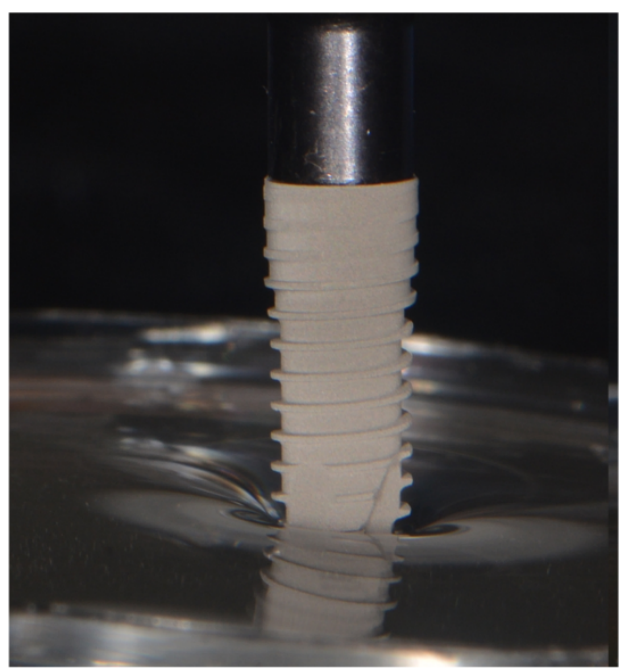

(A)

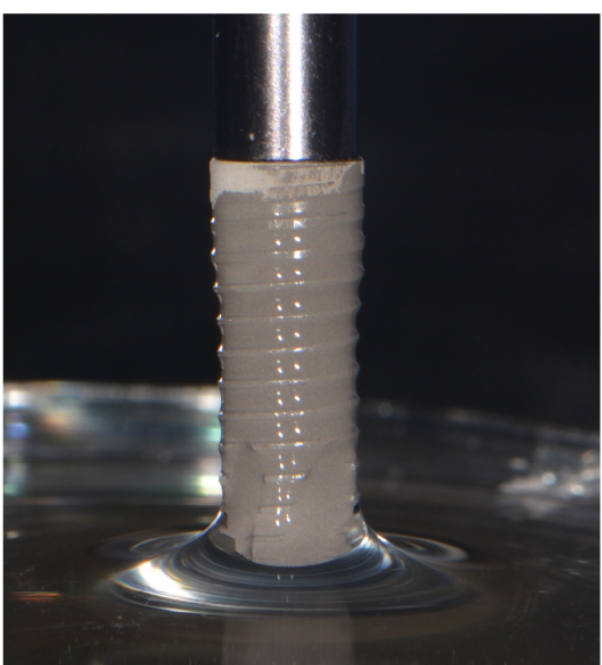

(B)

Figure 1. (A) Laboratory image of a hydrophobic implant surface in the non-irradiated group. (B) Laboratory image of hydrophilic changes in the UV irradiation group.

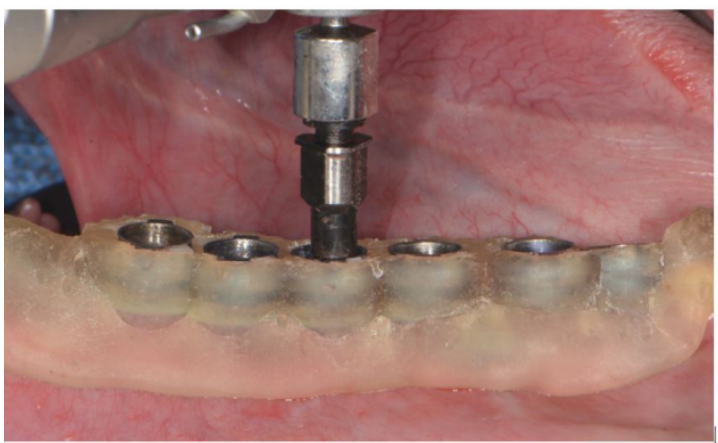

(A)

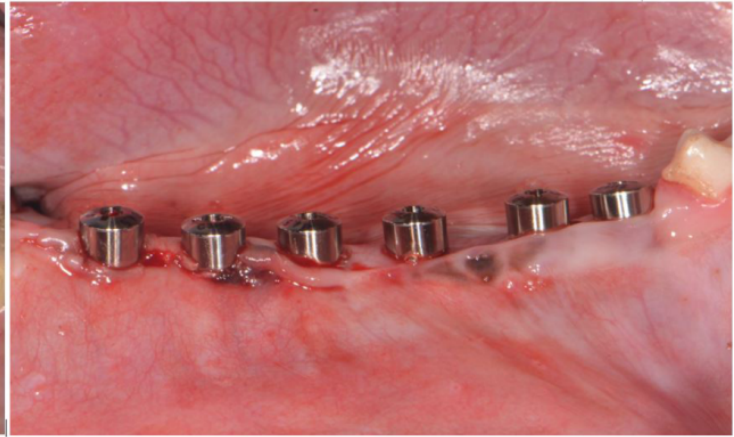

(B)

Figure 2. (A) Clinical image with surgical guide in place. (B) Clinical image with healing abutments in place. 


\subsection{Post-Experimental Management}

The canine subjects were fed a special soft diet to reduce trauma to the operative sites; all of the subjects were injected with antibiotics $(20 \mathrm{mg} / \mathrm{kg}$ Ceftriaxone Inj. B.R., Cephalosphorin, Boryung Parm., Seoul, Korea) intramuscularly for three days. The healing abutments were gently wiped with disinfectant (Hexamedin Soln ${ }^{\circledR}$, Chlorhexidine gluconate, Bukwang Parm., Seoul, Korea) every week to minimize infection.

\subsection{Clinical Evaluation}

Clinical evaluations were performed by measuring the IST values and taking periapical radiographs. IST values (Anycheck ${ }^{\circledR}$, Neobiotech, Seoul, Korea) were measured to assess implant stability at the time of implant placement and every seven days thereafter. The IST scores represented implant stability: high stability was identified if the IST score was $>70$, medium stability if the score was between 60 and 69, and low stability if the score was $<60$ [23].

\subsection{Histometric Analysis}

Two of the dogs were euthanized at 4 weeks and the other two at 12 weeks by injecting potassium chloride (Potassium Chloride Inj ${ }^{\circledR}$, Joong-Wae Parm., Seoul, Korea) into the jugular vein. The bone blocks with the implants were obtained from the dogs and fixed in $10 \%$ buffered formalin, dehydrated in ethanol, and embedded in methacrylate resin (Spur Low-Viscosity Embedding Media ${ }^{\circledR}$, Polyscience, Earrington, PA, USA). The bone blocks were cut parallel to the implant axis in a bucco-lingual plane with a High-precision Diamond Disc (Low Speed Diamond Wheel Saw 650 ${ }^{\circledR}$, SBT, Sanclement, CA, USA). Histologic sections $(30 \mu \mathrm{m})$ were stained with Goldner trichrome and evaluated under light microscopy. Using the imaging system (IBAS ${ }^{\circledR}$, Kontron, Germany), a histometric analysis were performed to measure the BIC lengths of five consecutive implant threads [24]. The calculated BIC lengths were converted to a percentage of the surface length of the implants in direct contact.

\subsection{Statistical Analysis}

The Wilcoxon signed rank test for paired samples was used to calculate the differences between the two groups. $p$-values $<0.05$ were considered statistically significant.

\section{Results}

All implants met the basic criteria for implant success; no signs of infection or inflammation were found around the bone block implants at the time of sacrifice. In addition, all implants in the bone block specimens were placed between the cortical bones, and the surrounding soft tissues of the healing abutments were intact (Figure 3).

None of the implants showed a significant difference in BIC measurement between the two groups at 4 and 12 weeks $(p>0.05)$. The mean BIC values were $44.6 \pm 10.8 \%$ at 4 weeks and $72.7 \pm 6.0 \%$ at 12 weeks in the UV-irradiated group. The mean BIC values were $39.6 \pm 13.2 \%$ at 4 weeks and $77.2 \pm 16.7 \%$ at 12 weeks in the non-irradiated group $(p>0.05)$ (Figure 4$)$.

The average IST values for the UV-irradiated group were as follows: $52.2 \pm 6.8 \%$ immediately after implantation, $45.6 \pm 4.1 \%$ at 1 week, $69.8 \pm 5.5 \%$ at 4 weeks, and $74.5 \pm 3.4 \%$ at 12 weeks $(p>0.05)$. The average IST values for the non-irradiated group were as follows: $48.3 \pm 4.6 \%$ immediately after implantation, $46.6 \pm 4.5 \%$ at 1 week, $60.3 \pm 11.6 \%$ at 4 weeks, and $70.6 \pm 3.3 \%$ at 12 weeks $(p>0.05)$ (Figure 5). 


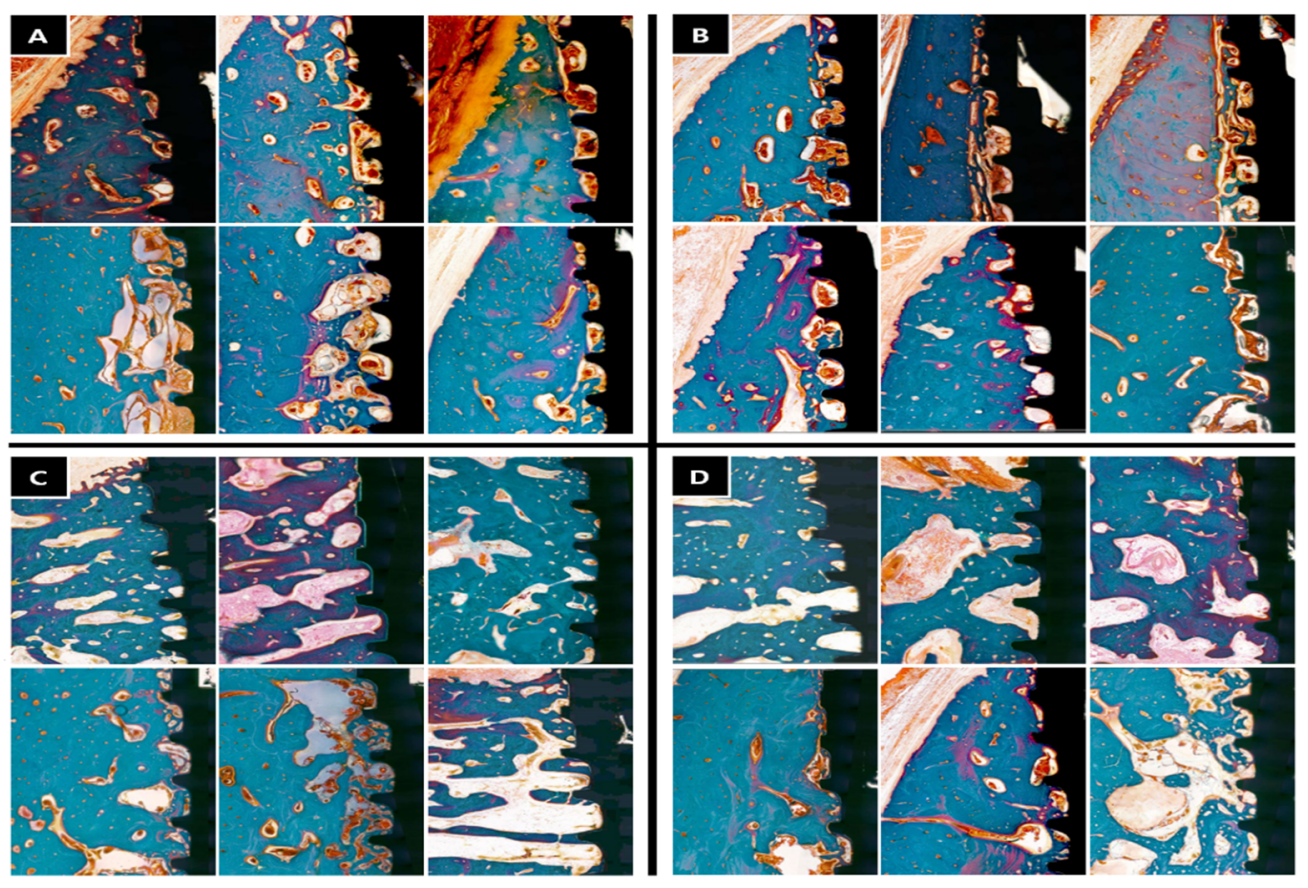

Figure 3. View of specimens: (A) ultraviolet irradiation group at 4 weeks, (B) non-irradiated group at 4 weeks, (C) ultraviolet irradiation group at 12 weeks, and (D) non-irradiated group at 12 weeks.

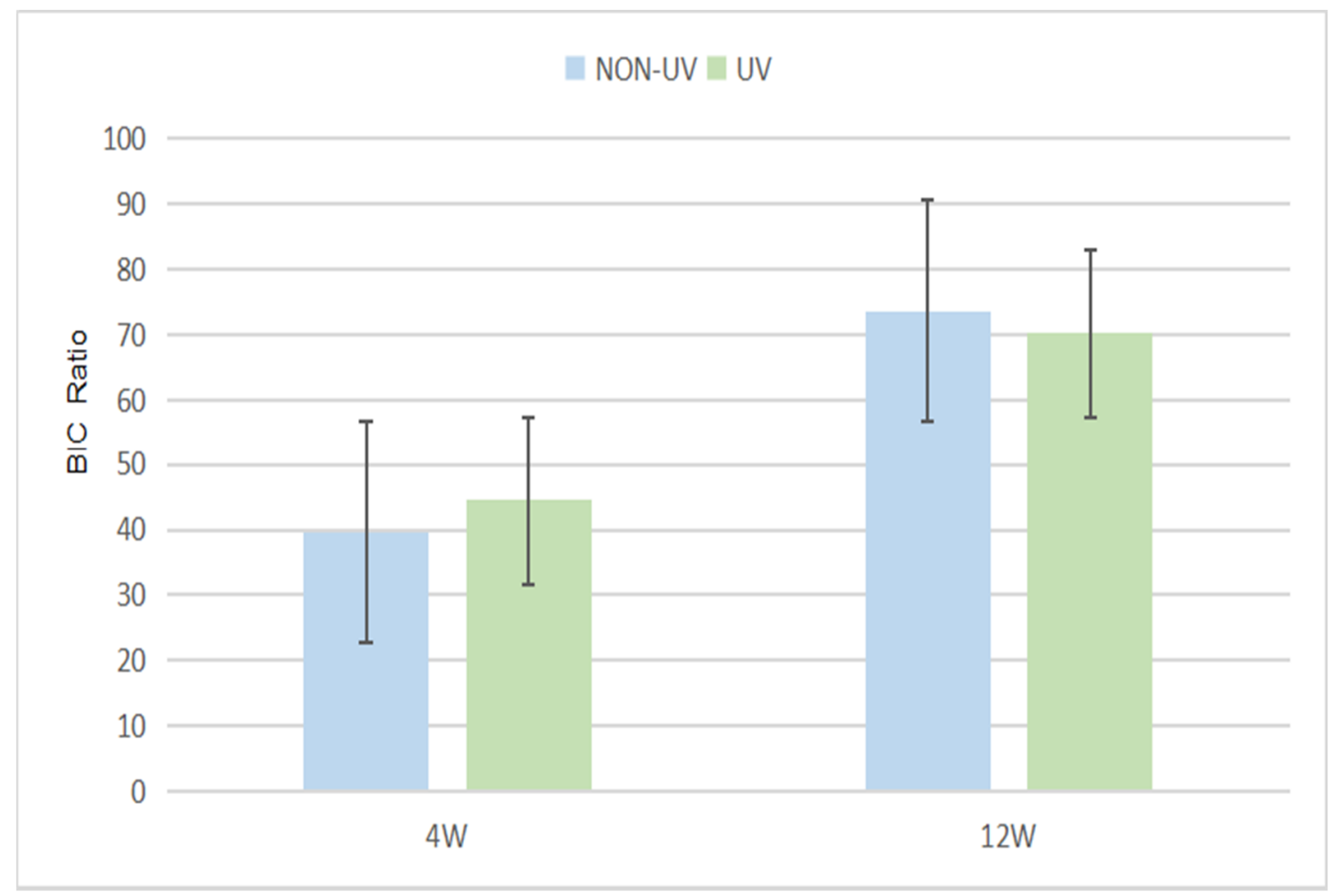

Figure 4. Comparative Results of Bone-to-Implant Contact Ratios at 4 and 12 weeks of implant placement. 


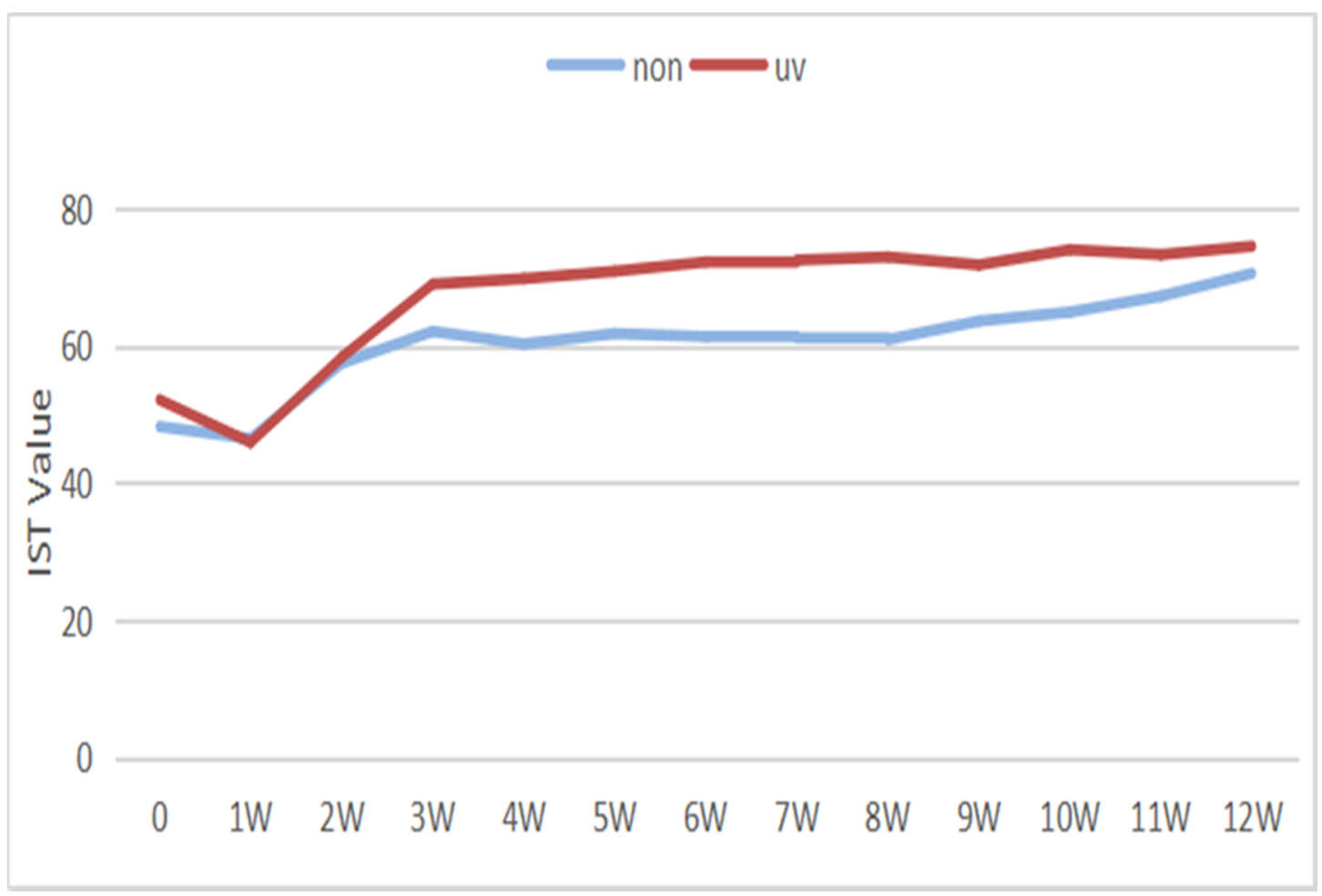

Figure 5. Comparative Results of weekly measured Implant Stability Test (IST) values.

\section{Discussion}

Several fundamental studies have identified the advantages of ultraviolet irradiation as follows: superhydrophilicity of titanium surfaces, removal of surface hydrocarbons, increased protein binding force, promoted osteoblastic activity, and promoted cell attachment and proliferation $[25,26]$. These phenomena are complementary to each other and occur with a close relationship [27]. Ultraviolet treatment can overcome degradation of the bioactivity of titanium implants through increasing surface wettability and initial fibroblast attachment, which has been proven through many studies $[18,26]$. However, we did not find any differences in osseointegration at 12 weeks. In addition, a $5 \%$ positive difference in BIC between the experimental and the control groups at 4 weeks of healing and a $5 \%$ negative difference at 12 weeks suggested that the UV treatment may not clinically help with osseointegration. We also found an average $70 \%$ BIC after 12 weeks of observation, which is the typical BIC value according to many other studies [28] and significantly lower than in other studies that reported an average of $98 \%$ BIC, superosseointegration, after a four-week period of UV irradiation [29]. This may be because other studies that reported higher percentage of BIC included the highest part of BIC, which is in the cortical compartment, and excluded the bone marrow area in which new bone formation could not be observed. However, in this study, to use the same baseline between the experimental group and the control group, the same consequent five implant threads were measured [24]. This result is reliable and can be strongly supported by other recent studies [30,31]. Mehl et al. noted that low BIC values were observed in both the UV-irradiated and non-irradiated groups, and the results showed no statistically significant differences [30]. Tejani et al. also found that osteoblast activity in UV-treated titanium samples is not significantly different from that of untreated samples, which contradicts the recently known effects of photofunctionalization [31].

Many studies were conducted to measure initial stability after implantation $[10,20,21]$. Typically, a Periotest ${ }^{\circledR}$ is conducted using PTV, which requires at least 16 strikes with a hitting-type device to verify if the implant can adversely affect the initial stage of stability after implant placement [20]. This can also cause discomfort to patients as they sometimes fail to achieve stable values even after 16 strikes. 
The following is an Osstell ${ }^{\circledR}$ that uses ISQ, a device that measures stability using magnetic resonance and requires a magnetized smart peg for measurement $[20,21]$. This means that the healing abutment must be separated for smart peg adaptation and, in the case of poor implant stability, the implant and healing abutment may simultaneously come out, causing failure [27]. For this reason, more frequent stability measurements may be required in implants with poor initial stability, but the implant failure potential may strain the user [32]. In addition, multiple smart pegs cannot be applied at once by each other's magnetism, which means that multiple implants cannot be measured simultaneously [32]. Lastly, Anycheck ${ }^{\circledR}$, which uses the IST value, was used in this study for several reasons, including that multiple implants can be measured at the same time, and the healing abutment does not need to be removed for each measurement [22].

According to the results, the average IST value in all groups showed a moderate decrease after one week of implantation, a rapid increase at two weeks, a peak value at four weeks, and a tendency to maintain peak value from four weeks. The slow reduction in IST value in the canine models after one week of implantation can be explained as the stability dip period [33], and our results have not been able to confirm the theory that UV irradiation can achieve higher BICs by reducing this stability dip [34], which supports our histomorphological results.

Many of the above studies demonstrated fractional cellular level changes [18,35], but the results of this study have not shown the superiority of UV irradiation in bone formation, potentially because new bone formation occurs in a more complex process than previously thought. The monocytes and macrophages are among the most abundant cells present in bone marrow, and play an important role in the immune response within the microenvironment [36]. However, Miron et al. stressed that macrophages not only affect immune responses, but also play a central role in osteogenesis and integration around the implant surfaces, thereby proving that the loss of macrophages could completely eliminate the bone forming potential of osteoblasts [37]. Takebe et al. stated that macrophages act as an important source for osteoinduction and affect the bone formation on the surface of implants by determining the biological responses [38]. Thus, photofunctionalization alone may not affect the overall process of osseointegration [30,31]. Osteogenesis around the endosseous implant is not facilitated independently by any one factor exclusively but, by the role of countless cytokines and proteins, the adsorption power of the clots and the long-term peri-implant environment such as cell occlusion, tissue integration, locoregional factors, and a number of systemic metabolism [39,40]. The true endpoint of a UV study would be to compare implant survival in the long term, which will guide future research. We also think that long-term clinical research should be conducted to overcome this limited result.

\section{Conclusions}

According to many studies, UV irradiation may increase the incipient surface energy at the cellular level but the UV-irradiated dental implants used in this study did not show an advantage in osseointegration. The lack of statistical difference in the BICs between experimental and control groups at early healing (four weeks) and at 12 weeks suggests that UV treatment alone may not clinically help with short- and long-term osseointegration. However, these findings revealed limited UV effects; thus, further investigation should be considered.

Author Contributions: Conceptualization, C.L.; methodology, B.-H.C.; data curation, H.-W.Y.; formal analysis, C.L.; funding acquisition, S.-M.J.; investigation, C.L. and H.-W.Y.; project administration, B.-H.C.; resources, S.-M.J.; supervision, B.-H.C.; writing-original draft, C.L.; writing-review and editing, C.L. All authors have read and agreed to the published version of the manuscript.

Funding: This work was supported by the Yonsei University Wonju Campus Future-Leading Research Initiative of 2020 (2020-52-0063).

Conflicts of Interest: The authors declare no conflicts of interest. 


\section{References}

1. Kang, D.; Kim, S.; Choi, Y.; Kim, Y. Repeated failure of implants at the same site: A retrospective clinical study. Maxillofac. Plast. Reconstr. Surg. 2019, 41, 27. [CrossRef] [PubMed]

2. Brånemark, P.I. Osseointegration and its experimental background. J. Prosthet. Dent. 1983, 50, $399-410$. [CrossRef]

3. Lee, S.C.; Song, W.S. Histomorphometric and Removal Torque values Comparision of Rough Surface Titanium Implants. J. Korean Assoc. Maxillofac. Plast. Reconstr. Surg. 2001, 23, 396-405.

4. Marco, F.; Milena, F.; Gianluca, G.; Vittoria, O. Peri-implant Osteogenesis in Health and Osteoporosis. Micron 2005, 36, 630-644. [CrossRef] [PubMed]

5. Soballe, K. Hydroxyapatite ceramic coating for bone implant fixation. Mechanical and histological studies in dogs. Acta Orthop. Scand. 1993, 64, 1-58. [CrossRef] [PubMed]

6. Linder, L.; Obrant, K.; Boivin, G. Osseointegration of Metallic Implants. II. Transmission Electron Microscopy in the Rabbit. Acta Orthop. Scand. 1989, 60, 135-139. [CrossRef] [PubMed]

7. Jun, S.H.; Park, C.; Hwang, S.; Lee, Y.K.; Zhou, C.; Jang, H.; Ryu, J. The influence of bone graft procedures on primary stability and bone change of implants placed in fresh extraction sockets. Maxillofac. Plast. Reconstr. Surg. 2018, 40, 8. [CrossRef]

8. Lim, J.S.; Kim, H.S.; Kook, M.S.; Park, H.J.; Oh, H.K. The Effect Of The Recipient Site Depth And Diameter On The Implant Primary Stability In Pig's Ribs. J. Korean Assoc. Maxillofac. Plast. Reconstr. Surg. 2007, 29, 301-308.

9. Alam, N.; Anand, N.; Chandrasekaran, S.; Kovendhan, Y. Is proimary stability the gold standard factor in implant success. Dent. Hypoth. 2014, 5, 70-74.

10. Javed, F.; Ahmed, H.B.; Crespi, R.; Romanos, G.E. Role of primary stability for successful osseointegration of dental implants: Factors of influence and evaluation. Interv. Med. Appl. Sci. 2013, 5, 162-167. [CrossRef]

11. Choi, Y.; Jun, S.; Song, Y.; Chang, M.; Kwon, J. CT Scanning and Dental Implant. Tech. Appl. 2011, 13, $230-250$.

12. Schwartz, Z.; Lohmann, C.H.; Oefinger, J.; Bonewald, L.F.; Dean, D.D.; Boyan, B.D. Implant surface characteristics modulate differentiation behavior of cells in the ossteoblastic Lineage. Adv. Dent. Res. 1999, 13, 38-48. [CrossRef] [PubMed]

13. Kang, C.G.; Park, Y.B.; Choi, H.; Oh, S.; Lee, K.W.; Choi, S.H.; Shim, J.S. Osseointegration of implants surface-treated with various diameters of $\mathrm{TiO}_{2}$ nanotubes in rabbit. J. Nanomater. 2015, 2015, 1-11.

14. Parekh, R.B.; Shetty, O.; Tabassum, R. Surface modifications for endosseous dental implants. Int. J. Oral Implantol. Clin. Res. 2012, 3, 116-121.

15. Kim, M.; Yun, P.; Chang, N.; Kim, Y. The long-term evaluation of the prognosis of implants with acid-etched surfaces sandblasted with alumina: A retrospective clinical study. Maxillofac. Plast. Reconstr. Surg. 2020, 42, 10. [CrossRef]

16. Yadav, V.V.S.; Reddy, P.S.; Reddy, A.S.K.; Jain, A.R.; Anjaneyulu, K. Evaluation and comparison of surface roughness levels, surface wettability, and surface configuration of commercially pure titanium surface. Biol. Med. 2016, 9, 1-5. [CrossRef]

17. Att, W.; Ogawa, T. Biological aging of implant surfaces and their restoration with ultraviolet light treatment. Int. J. Oral Maxillofac. Implant. 2012, 27, 753-761.

18. Suzuki, T.; Hori, N.; Att, W.; Kubo, K.; Iwasa, F.; Ueno, T.; Maeda, H.; Ogawa, T. Ultraviolet treatment overcomes time-related degrading bioactivity of titanium. Tissue Eng. Part A 2009, 15, 3679-3688. [CrossRef]

19. Suzuki, S.; Kobayashi, H.; Ogawa, T. Implant stability change and osseointegration speed of immediately loaded photofunctionalized implants. Implant. Dent. 2013, 22, 481-490. [CrossRef]

20. Atsumi, M.; Park, S.H.; Wang, H.L. Methods used to assess implant stability: Current status. Int. J. Oral Maxillofac. Implant. 2007, 22, 743-754.

21. Balshi, S.F.; Allen, F.D.; Wolfinger, G.J.; Balshi, T.J. A resonance frequency analysis assessment of maxillary and mandibular immediately loaded implants. Int. J. Oral Maxillofac. Implant. 2005, 20, 584-594.

22. Park, Y.; Leesungbok, R.; Lee, S.; Paek, J.; Lee, J. Differences in percussion-type measurements of implant stability according to height of healing abutments and measurement angle. J. Korean Acad. Prosthodont. 2018, 56, 278-286. [CrossRef]

23. Muhamad, A.; Georges, C.; Mustafa, M.; Abdulgani, A. Implant stability: Methods and recent advances. IOSR J. Dent. Med. Sci. 2017, 16, 13-23. 
24. Hirota, M.; Ikeda, T.; Tabuchi, M.; Iwai, T.; Tobnai, I.; Ogawa, T. Effect of ultraviolet-mediated photofunctionalization for bone formation around medical titanium mesh. J. Oral Maxillofac. Surg. 2014, 72, 1691-1702. [CrossRef] [PubMed]

25. Ueno, T.; Yamada, M.; Suzuki, T.; Minamikawa, H.; Sato, N.; Hori, N.; Takeuchi, K.; Hattori, M.; Ogawa, T. Enhancement of bone-titanium integration profile with UV-photofunctionalized titanium in a gap healing model. Biomaterials 2010, 31, 1546-1557. [CrossRef] [PubMed]

26. Petzold, C.; Rubert, M.; Lyngstadaas, S.P.; Ellingsen, J.E.; Monjo, M. In vivo performance of titanium implants functionalized with eicosapentaenoic acid and UV irradiation. J. Biomed. Mater. Res. A 2011, 96, 83-92. [CrossRef] [PubMed]

27. De Maeztu, M.A.; Braceras, I.; Alava, J.I.; Gay-Escoda, C. Improvement of osseointegration of titanium dental implant surfaces modified with CO ions: A comparative histomorphometric study in beagle dogs. Int. J. Oral Maxillofac. Surg. 2008, 37, 441-447. [CrossRef]

28. Yassir, A.; Hag, E.; Cheng, Y. Achieving superosseointegration: The photofunctionalization effect. Dentistry 2017, 7, 1-8.

29. Ogawa, T. Ultraviolet photofunctionalization of titanium implants. Int. J. Oral Maxillofac. Implant. 2014, 29, 95-102. [CrossRef]

30. Mehl, C.; Kern, M.; Neumann, F.; Bahr, T.; Wiltfang, J.; Gassling, V. Effect of ultraviolet photofunctionalization of dental titanium implants on osseointegration. J. Zhejiang Univ. Sci. B 2018, 19, 525-534. [CrossRef]

31. Tejani, H.; Venugopal, A.; Yu, W.; Kyung, H.M. Effects of UV treatment on orthodontic microimplant surface after autoclaving. Korean J. Dent. Mater. 2017, 44, 119-127. [CrossRef]

32. Park, J.; Lee, J.; Kim, S.; Lee, J. Implant stability-Measuring devices and randomized clinical trial for ISQ value change pattern measured from two different directions by magnetic RFA. Implant. Dent A Rapidly Evol. Pract. 2011, 5, 111-128.

33. Raghavendra, S.; Wood, M.C.; Taylor, T.D. Early wound healing around endosseous implants: A literature review. Int. J. Oral Maxillofac. Implant. 2005, 20, 425-431.

34. Verborgt, O.; Gibson, G.J.; Schaffler, M.B. Loss of osteocyte integrity in association with microdamage and bone remodeling after fatigue in vivo. J. Bone Miner Res. 2000, 15, 60-67. [CrossRef]

35. Minamikawa, H.; Ikeda, T.; Att, W.; Hagiwara, Y.; Hirota, M.; Tabuchi, M.; Aita, H.; Park, W.; Ogawa, T. Photofunctionalization increases the bioactivity and osteoconductivity of the titanium alloy $\mathrm{Ti}_{6} \mathrm{Al}_{4} \mathrm{~V}$. J. Biomed. Mater. Res. 2014, 102, 3618-3630. [CrossRef] [PubMed]

36. Garcia-Contreras, R.; Kanagawa, S.; Beppu, Y.; Nagao, T.; Sakagami, H.; Nakajima, H.; Shimada, J.; Adachi, K. Morphological features of osteoblasts cultured on ultraviolet-irradiated titanium plates. In Vivo 2011, 25, 649-656. [PubMed]

37. Miron, R.J.; Bosshardt, D.D. OsteoMacs: Key players around bone biomaterials. Biomaterials 2016, 82, 1-19. [CrossRef]

38. Takebe, J.; Champagne, C.M.; Offenbacher, S.; Ishibashi, K.; Cooper, L.F. Titanium surface topography alters cell shape and modulates bone morphogenetic protein 2 expression in the J774A.1 macrophage cell line. J. Biomed. Mater. Res. A 2003, 64, 207-216. [CrossRef]

39. Scantlebury, T.V. 1982-1992: A decade of technology development for guided tissue regeneration. J. Periodontol. 1993, 64, 1129-1137. [CrossRef]

40. Insua, A.; Monje, A.; Wang, H.; Miron, R.J. Basis of bone metabolism around dental implants during osseointegration and peri-implant bone loss. J. Biomed. Mater. Res. A 2017, 105, 2075-2089. [CrossRef]

(C) 2020 by the authors. Licensee MDPI, Basel, Switzerland. This article is an open access article distributed under the terms and conditions of the Creative Commons Attribution (CC BY) license (http://creativecommons.org/licenses/by/4.0/). 